(C) 2015. This manuscript version is made available under the CC-BY-NC-ND 4.0

license http://creativecommons.org/licenses/by-nc-nd/4.0/

\title{
Hyperbolic Language and its Relation to Metaphor and Irony
}

\begin{abstract}
Hyperbolic use of language is very frequent but has seldom been thought worthy of serious analytical attention. Hyperbole is usually treated as a minor trope which belongs with one or the other of the two dominant figurative uses of language, metaphor and irony. In this paper, we examine the range of ways in which hyperbole is manifest, in both its 'pure' uses and its prevalent co-occurrences with other tropes. We conclude that it does not align closely with either metaphor or irony but is a distinctive figure of speech in its own right, characterized by the blatant exaggeration of a relevant scalar property for the purpose of expressing an evaluation of a state of affairs. The relative simplicity of hyperbole enables its exploitation of a range of independent mechanisms of non-literal linguistic communication including loose use, metaphor, simile, and expressions of ironical and other attitudes.
\end{abstract}

Keywords: hyperbole, metaphor, irony, quantitative shift, qualitative shift, evaluative component

\section{Introduction}

Hyperbole is one of the most widely used figures of speech, and yet it remains significantly understudied in comparison with other figures like metaphor, simile, metonymy and irony. The reason for this may be that it is considered a less interesting, substantial or effective use of language, perhaps even facile or trivial, as compared with these other figures, whose employment requires greater verbal skill and whose effects on hearers and readers are more powerful. But whatever its status as a figure may be, 
hyperbole's prevalence and familiarity are enough to raise the question of how it works, and this question, as we will indicate, has not yet been adequately answered. Equally unresolved is the question of how it interacts with the many other figures with which it appears to combine.

In the extensive existing literature on figures of speech, metaphor and irony are often taken to be the two central tropes and to be importantly different from each other in the ways they work and the interpretive effects they have. Other figures are then often classified according to whether they pattern more with metaphor or more with irony. So, for instance, simile is taken to cluster with metaphor and understatement (meiosis) with irony. There is an intriguing and quite basic point of disagreement in the scanty existing literature on hyperbole, namely, whether it works more like metaphor or more like irony, so whether it lines up with a family of metaphor-like tropes or a family of irony-like tropes. The few philosophers who have mentioned hyperbole have tended to place it with irony. For example, Nelson Goodman and Robert Fogelin both provide brief analyses of hyperbole and place it alongside irony and understatement. Josef Stern and Sam Guttenplan don't discuss hyperbole in its own right, but, in the course of their booklength studies of metaphor, they too place hyperbole together with irony as distinct from metaphor. Similarly, psychologists and linguists interested in the uses and cognitive effects of non-literal language or in its development in children have taken hyperbole to belong with irony, sometimes in fact assuming that it is a kind of irony, e.g. Herb Clark, Herbert Colston and colleagues, Ray Gibbs and John Legitt, Eva Filippova and Janet Astington.

Relevance theorists, on the other hand, have situated hyperbole with metaphor, treating both figures as instances of loose talk, whose interpretation requires the construction of an occasion-specific (or ad hoc) concept (Sperber and Wilson 1985/86, 1986/95, 2008 ${ }^{1}$; Wilson and Carston 2007). Indeed, Sperber and Wilson have argued that

\footnotetext{
${ }^{1}$ The discussion of hyperbole and metaphor in Sperber and Wilson (1985/86, 1986/95) pre-dates the account in terms of ad hoc concepts, but clearly states the position that hyperbole and metaphor are cases of loose use with no discontinuity between them. This claim is carried over into the later ad hoc concept account, which is most clearly articulated in Sperber and Wilson (2008); it is this, most current, version of the theory that we are working with.
} 
hyperbole and metaphor are essentially continuous; that is, they are 'not genuinely distinct categories, at least from descriptive, psycholinguistic, or pragmatic points of view' (2008: 95). Irony, by contrast, works quite differently on this account: it is treated as an echoic use of language, and hence as essentially metarepresentational in a way that metaphor and hyperbole are not (Wilson and Sperber 1992, 2012; Wilson 2013).

Clearly, at least one of these views cannot be right. So the question presses: where does hyperbole belong - with metaphor or with irony (or with neither)? We shall use this 'metaphor or irony?' question to structure our investigation of hyperbole, but our ultimate conclusion will be that, while the reasoning of each camp provides important insights which any complete account must accommodate, hyperbolic language use is a distinctive phenomenon in its own right and one that combines in interesting ways with a range of other figures of speech. ${ }^{2}$

The rest of the paper is structured as follows. In section 2, we start with some initial (pre-theoretical) observations about hyperbole and provide some relatively clear examples to work with, including cases that involve hyperbole co-occurring with other figures; in section 3 , we set out some necessary background concerning the distinction between metaphor and irony. Then, in sections 4 and 5, we assess the lines of thought that have led some theorists to align hyperbole with irony and others to align it with metaphor, extracting the key insights of these opposing positions. Finally, in section 6 , we draw together the conclusions of the earlier sections and argue that there are reasons to think that hyperbole is neither like metaphor nor like irony, but that it functions in a distinctive way that exploits a range of kinds of language use (loose uses, comparisons, categorizations, and expressions of ironical and other kinds of attitude).

\footnotetext{
${ }^{2}$ We want to emphasise from the outset that the uses of language labeled by these terms 'hyperbole', 'metaphor', irony', 'metonymy', and so on - are very unlikely to delineate natural or uniform classes, but, like virtually all theorists before us, we take widely agreed prototypical instances falling in these intuitive folk categories as our point of departure. The long-term goal is to achieve analyses of cases in terms of the mental processes and mechanisms employed in their expression and interpretation, and we do not expect the taxonomy thereby established to mesh perfectly with any of the pretheoretic taxonomies, among which there is in any case considerable variation.
} 


\section{Preliminary observations and examples}

Let's start with a few examples of 'pure' hyperbole, that is, cases that are clearly hyperbolic and do not involve any other kind of non-literal language use:

(1) My piece of cake is tiny.

(said by a 10-year old boy after comparing his moderate slice of cake with the slightly bigger one on his older sister's plate)

(2) It's impossible.

(said by a first-year undergraduate about a challenging logic problem)

(3) There were a million people ahead of me in the queue.

(said after standing in a line that stretched about 40 feet)

(4) Sara's bedroom is the size of Cornwall.

(said while describing Sara's new living arrangements (example due to Deirdre Wilson))

Each of these examples exhibits what is arguably the defining feature of a hyperbolic utterance, namely, an overt and blatant exaggeration of some property or characteristic. The speaker does not intend to be taken literally and the hearer recognizes this. So, assuming the communication is successful, both parties recognize that the literal description is an overstatement of the actual state of affairs: they both take it that the piece of cake is a reasonable size for a 10-year old child; that the logic problem is difficult but unquestionably solvable; that the queue was only just out the door of the theatre; that Sara's bedroom is larger than a typically sized bedroom, but certainly not the size of Cornwall (>1300 square miles!). It is these weaker scaled-down descriptions to which the speaker communicates her commitment but, of course, given that she has chosen to use the much stronger versions, she is seeking to convey some other kind of interpretive effect as well. This further effect does not seem to consist of a distinct thought or proposition but rather to be something evaluative or emotional; we look more closely at this key feature of hyperbole in section 4 .

These examples have a number of other characteristics that are worth noting. In 
each case there is a clear scale along which we can make an adjustment: size (of cakes/bedrooms); difficulty (of problems); length (of queues). At the same time, each of these exaggerations can tolerate a fair bit of flexibility in its expression, so, for instance, the speaker of (3) might equally successfully have employed any one of the following to communicate that the number of people in the queue was very large: 'hundreds of people', 'thousands of people', 'millions of people', 'endless numbers of people'. Similarly, the boy in (1) might just as well have complained that his piece of cake was 'minuscule', 'microscopic' or 'infinitesimal'. Each option provides an obvious and overt exaggeration of the actual state of affairs, although this is not to say that it makes no difference which description one chooses. On the contrary, differences in the degree of exaggeration might convey something about the speaker's attitude towards the situation (e.g. by calling his slice of case 'microscopic' rather than 'tiny', the boy might convey more forcefully his dissatisfaction with it). ${ }^{3}$ Similarly, particularly specific or unexpected descriptions may provoke a greater degree of humor than more mundane variations (contrast (4) with the more pedestrian 'Sara's bedroom is enormous').

Finally, a striking feature of hyperbole is how readily it seems to combine with other non-literal uses of language. It co-occurs with just about every other common form of figurative language (except understatement, which seems to be its logical opposite); no other figure co-occurs to the same extent. ${ }^{4}$

(5) That child is the devil incarnate. (hyperbole and metaphor)

(6) They go about together like Siamese twins. (hyperbole and simile)

\footnotetext{
${ }^{3}$ In his interesting study of 'extreme case formulations' (e.g. 'an endless line of people', 'the worst party ever'), Norrick (2004) shows that these differ in their distribution and in some of their contextual effects from other (non-extreme) cases of hyperbole. For the purposes of this paper, we abstract away from these differences.

${ }^{4}$ In a corpus study of recent American short stories, Kreuz et al (1996) found that, compared with a range of common figures of speech, hyperbole was second in frequency of occurrence (with metaphor coming first), but co-occurred with other tropes significantly more frequently than any other figure. Eighty percent of the co-occurrences found involved hyperbole (and it co-occurred with every other figure except understatement), whereas metaphor (the second most common figure to co-occur) was found in only $50 \%$ of the cases and the vast majority of those were co-occurrences with hyperbole.
} 
(7) The gargantuan paunch over there is my step-father. (hyperbole and metonymy)

(8) It's the end of the world. (hyperbole and irony)

[describing someone's angry reaction when he finds he's got a parking fine]

(9) Those tickets cost an arm and a leg. (hyperbole and idiom)

(10) Money is the root of all evil. (hyperbole and proverb)

[in response to a situation in which someone has claimed a little more on their expenses than they were strictly entitled to]

Summing up, hyperbole is a trope which involves deliberate and overt exaggeration (along a particular scale), it is flexible with regard to how it can be expressed (allowing for degrees of exaggeration) and it is capable of combining with a range of other tropes. It might seem that there is little more to be said about hyperbole beyond this characterization, but we think a deeper appreciation of its use and how it works can be gained by looking at how it relates to other tropes. As mentioned in the introduction, the existing discussions of hyperbole in the literature tend to situate it with either irony or metaphor, where these two figures are taken to be clearly distinct from one another. Examining more closely why hyperbole has been classified as like irony by some theorists and as like metaphor by others will give us a better understanding of the distinctive nature of this use of language. ${ }^{5}$ So before considering the reasoning behind these different classifications of hyperbole, let's look at why and how metaphor and irony are judged to be such different figures, each often being taken as the dominant member of two separate families of tropes.

\footnotetext{
${ }^{5}$ In accordance with an objection from an anonymous referee for the journal, we acknowledge that there are a number of empirical studies that investigate hyperbole as a stand-alone trope, including Cano Mora (2009), Kreuz et al. (1998), McCarthy and Carter (2004), and Norrick (2004). These are of undoubted interest for the light they shed on the different roles of hyperbole in discourse and on its cognitive, social and emotional effects on recipients, but they lie outside our concern here which is to resolve the issue of how hyperbole can be analysed as akin to both metaphor and irony.
} 


\section{The distinction between metaphor and irony}

Clearly, metaphor and irony have some basic features in common: they are both nonliteral uses of language and so involve communicating something other than the proposition literally expressed by the uttered sentence. However, that's about as far as the similarities extend and most current theoretical accounts of metaphor and irony emphasise their distinctive characteristics. There is also a growing body of empirical evidence indicating differences in the kinds of processes by which they are understood. We will briefly summarize the key distinctions made in a range of accounts and try to draw out from them a characterization of the fundamental difference between the two tropes.

Relevance theorists analyze metaphorical uses of language as falling within the class of loose uses and as requiring a hearer to form an occasion-specific sense of a word or phrase (an ad hoc concept). For instance, an utterance of 'Mary is a chameleon' communicates an explicature (a truth-conditional content) whose predicate constituent is the concept CHAMELEON*, which has a broader denotation than that of the lexically encoded concept CHAMELEON, as it includes certain human beings as well as the species of lizard. Irony, on the other hand, involves echoing a thought which is similar in content to the one literally expressed and conveying a dissociative attitude towards that thought (Sperber \& Wilson 2008; Wilson \& Sperber 2012). Coming from a quite different theoretical perspective, the philosopher Josef Stern argues that metaphorical language involves an operation which assigns to components of the sentence uttered a non-constant character (via the 'Mthat' operator), while irony operates on the propositional contents of the utterance to yield different propositional contents. Thus, for both these theorists, metaphorical interpretations are semantic (in the sense that they affect truth-conditional (or explicit) content) while ironical interpretations are post-semantic or pragmatic (see Stern 2000, especially pp. 236-238). ${ }^{6}$

${ }^{6}$ Fogelin (1988/2011) takes a very different stance, but also finds the two tropes quite distinct in nature: metaphor is an instance of figurative comparison, that is, the uttered sentence expresses an elliptical comparison (identical in meaning to its non-elliptical counterpart simile), whereas irony is an instance of figurative predication, such that 
A quite widely held view among pragmaticists, psychologists and philosophers is that irony, but not metaphor, involves an act of overtly pretending to produce a certain speech act. Herb Clark, for example, has analyzed irony as a 'staged communicative act', that is, a kind of joint pretense, in which a hearer must recognize that the act of assertion (of, say, 'John is a fine friend') is staged or simulated and infer what the speaker means by her pretend act (Clark 1996; see also Clark \& Gerrig 1984). While he thinks a number of other figures involve staging/pretense, he does not include metaphor among them and inclines to a view of metaphor that sees it as involving the ability to make and comprehend analogies (p.c.). The philosopher, Francois Recanati, who advocates an account of metaphor according to which it is a case of word meaning modulation which affects the content of the proposition explicitly communicated, maintains a similar view to Clark on irony: "one must discern two 'layers' within the primary meaning of the utterance: the surface speech act which the speaker pretends to perform, and the ironical act of staging the performance of that speech act." (Recanati 2004: 77). ${ }^{7}$

The psychologist Sam Glucksberg's view of metaphor is well-known: he maintains that metaphorically used words are cases of dual reference, so, for instance, in the utterance 'My job is a jail', the word 'jail' denotes both its literal referent and a superordinate category of confining, constraining entities of which the literal referent is a prototypical instance (Glucksberg 2001). Together with colleagues (see KumonNakamura, Glucksberg and Brown 1995), he takes a very different view of irony, analyzing it as a case of 'allusional pretense', an account which combines some aspects of Clark's pretense view and some aspects of the relevance-theoretic echoic view of irony.

What all of these accounts point to is a difference in the representational natures of metaphor and irony: while metaphor is essentially used to describe the world (or our experience of it), irony is used to express an attitude to some representation of the world which is not put forward as one that the speaker endorses.

A difference in representational complexity of this sort is also supported by a

reception of the literal content expressed by the uttered sentence provokes a 'correcting judgment' on the part of the hearer.

7 Another important account of irony in terms of pretense has been developed by the philosopher Gregory Currie (see, for instance, Currie (2006)). 
variety of empirical studies. For example, Colston and Gibbs (2002) conclude from a series of experiments on adults' comprehension of identical sentences used either metaphorically or ironically that irony involves different comprehension processes from metaphor. Irony takes significantly longer to understand than metaphor and this, they claim, is at least partly because of the 'metarepresentational reasoning' needed in order to understand ironical, but not metaphorical, uses of language. Similarly, research on children's developing abilities to produce and comprehend metaphor and irony support the view that the two tropes are fundamentally different ways of using language nonliterally. It is well attested that in typical development, children's facility with irony comes considerably later than their ability to produce and understand metaphor and this is thought to be due to the quite different cognitive and pragmatic demands they make. In her early detailed comparison of children's abilities with metaphor and irony, Ellen Winner concluded that 'children interpret the two chief forms of nonliteral language in qualitatively different ways' (Winner 1988: 183). ${ }^{8}$ See also Wilson (2013) for a survey of developmental work on this issue over the past 25 years, all of which seems to corroborate the view that these two kinds of non-literal language use have their own distinct developmental trajectories.

A third line of evidence comes from clinical studies of populations with impaired use and/or comprehension of non-literal language. For instance, it has been shown that metaphor comprehension in some individuals on the autism spectrum is preserved at the same time that irony comprehension is impaired (while the reverse is never the case) and it has been suggested that this pattern correlates with the level of intact theory of mind capacities possessed by the individuals in question (irony requiring a higher order of mentalizing capacity than metaphor, e.g. Happé 1993, Norbury 2005). A detailed study of schizophrenic people's comprehension of metaphor and irony reached the interesting conclusion that, although the group tested manifested difficulties with both kinds of nonliteral use, the source of the difficulty was quite different in the two cases: while problems with irony correlated with, and appeared to be caused by, a general deficit in

\footnotetext{
${ }^{8}$ In the preface to her study, Winner distinguishes metaphor and irony developmentally as follows: 'Metaphor is a window on children's classification skills, irony on children's abilities to attribute beliefs and intentions to others' (Winner 1988: vi).
} 
theory of mind reasoning, difficulties with metaphor seemed to be independent of mindreading abilities and better explained as caused by degraded or disorganized 'semantic networks' or conceptual knowledge systems (Langdon et al. 2002).

These various empirical findings, then, provide strong support for the position that there are striking differences in the processing mechanisms employed in the comprehension of the two figures.

Let us try to sum up the picture of the metaphor/irony difference that emerges from these diverse fields and frameworks. One conclusion that virtually all of the studies and theories point to is the idea that the meaning communicated by a metaphorical use contributes to the descriptive (propositional) content of the utterance, that is, there is a sense in which the metaphorical meaning gets 'lodged in the words', as David Hills (1997: 127) puts it, in a way that does not happen with ironical uses of language. ${ }^{9} \mathrm{We}$ think the following is a reasonably theory-neutral characterization of this key difference between the two tropes: understanding a metaphorical use centrally involves adjusting the interpretation of (some part of) the uttered sentence itself, while interpretation of an ironical use involves metarepresenting the proposition literally expressed by the uttered sentence and expressing a dissociative attitude of some sort toward it (from which further propositional meaning, manifest as conversational implicatures, may follow).

With this basic distinction in place, we are now in a position to examine the opposition between views according to which hyperbole is of a piece with irony and according to which it is of a piece with metaphor.

\section{Hyperbole and irony}

Among those who have grouped hyperbole with irony, two sorts of classifications have been made. A number of philosophers (e.g. Goodman, Fogelin, Stern, and Guttenplan) have treated hyperbole as distinct from, but bearing a family resemblance to, irony. A

\footnotetext{
${ }^{9}$ This contrast is reflected in records of the way word meanings change over time: dictionaries list many established word senses that started out as metaphors, indeed 'metaphorical transfer' is seen as a key driver of meaning change, while, as far as we are aware, there are no new senses of words that have arisen from ironical usage.
} 
number of psychologists, by contrast, have adopted the much stronger position that hyperbole is a kind of irony. For example, in an investigation of responses to attitudinally charged uses of language, Leggitt and Gibbs (2000: 1) talk of 'sarcasm, overstatement (hyperbole), understatement, satire and rhetorical questions' as 'different kinds of ironic language'. This position is also endorsed in some of the literature on children's developing competence with non-literal language, e.g. 'This study examined how children use and understand various forms of irony (sarcasm, hyperbole, understatement, and rhetorical questions) ...' (Recchia et al. 2010: 255). ${ }^{10}$ In this section, we first address this stronger position, which we think is clearly incorrect - hyperbole is not inherently ironical - and then move to the weaker view that takes hyperbole to belong in the irony family, a more plausible position and one for which there is some argument.

There are many examples of hyperbolic use where the speaker is clearly endorsing a proposition which involves only the pragmatic weakening of a hyperbolically used word. Consider, for example, saying 'It's boiling outside', intending to convey 'It's uncomfortably hot outside'. Similarly, all of the opening examples (1)-(4) above have unambiguously non-ironical uses (e.g. where the appropriate paraphrases are (1) 'the piece of cake is smaller than I wanted', (2) 'the problem is more difficult than I expected', (3) 'there were many more people in the queue than I expected/wanted', and (4) 'Sara's bedroom is absurdly large'). None of these expresses an ironical attitude or implicates the contrary or contradictory of the proposition expressed (e.g. that it's cold outside, that the piece of cake is large, etc.). A range of uncontroversial examples of hyperbole, then, shows that any outright assimilation of hyperbole to irony cannot be right.

This conclusion is further supported by recent work of Deirdre Wilson, in which she argues against treating hyperbole as a species of irony on the grounds that it doesn't exhibit any of the following three characteristic features of irony (Wilson 2013). First, irony typically involves the expression of an attitude of mockery or scorn towards (or at least demurral from) the viewpoint literally expressed:

${ }^{10}$ Similarly, in their study of children's use and understanding of 'discourse irony', Filippova and Astington (2010) include cases of hyperbole. In all of these papers it is simply presupposed, without argument or comment, that hyperbole is a form of irony. 
(11) Well done. (said after someone clumsily drops and breaks something valuable)

(12) What lovely weather. (said while it's raining hard)

Second, irony is (optionally) accompanied by a characteristic tone of voice: a flat or deadpan intonation, with slower tempo, lower pitch level, and greater intensity (than for a non-ironical utterance of the same sentence). ${ }^{11}$ Consider, for instance, how someone might utter either of the examples in (11) or (12). The third characteristic feature of irony is its 'normative bias', that is, irony is more often used to register a criticism or a complaint than to convey praise or some other positive stance. This is because it can easily exploit socially shared norms about how things should be (e.g. the weather should be fair, friends should be loyal, lectures should be interesting, work should be done well) to convey a negative attitude towards violations of these norms. Using irony to convey a positive assessment is less common because it requires a specific context or some preliminary 'staging' in order to come off successfully: for instance, you could achieve irony with an utterance of 'What a terrible friend' only if some particular (nonnormative) expectation had been established (that the friend in question was bound to treat you badly) and subsequently this pessimistic expectation had been defied by the friend going out of her way to be very helpful. ${ }^{12}$

It's pretty clear that typical cases of hyperbole don't involve any of these three features. Consider the canonical cases of 'pure' hyperbole in (1)-(4), repeated here for convenience:

(1) My piece of cake is tiny.

${ }^{11}$ This is, of course, no more than a tendency and there is quite a lot of variability in the prosody of ironic utterances depending in part on the specific attitude expressed (from the bitterly scornful to the gently demurring). The more sarcastic instances tend to employ a pitch contour with marked fall-rise contrast (see Rockwell 2000, Bryant 2010).

12 This is a nice piece of evidence in support of the 'echoic' account of irony (Wilson and Sperber 1992, 2012): prevailing social norms and universal human expectations/hopes are always available to be echoed, while expectations of negative states of affairs (bad weather, disloyal friends, poor performances of one sort of another) are not and require specific contexts if they are to be echoed. 
(2) This logic problem is impossible.

(3) There were a million people ahead of me in the queue.

(4) Sara's bedroom is the size of Cornwall.

First, none of these examples (considered in the contexts given earlier) conveys an attitude of scorn, mockery, or contempt towards the viewpoint literally expressed. There may well be a negative attitude of some sort expressed but it concerns the state of affairs being described (the size of the piece of cake, the difficulty of the logic problem, etc.). If these sentences did convey mockery toward the proposition literally expressed, we' $d$ be inclined to judge them as ironical as well as hyperbolic. For example, if (1) were uttered by someone on a slimming diet who, having asked for a small piece of cake, has been handed a sizable slice, we would likely judge the utterance to be ironic. But in that case, the presence of the characteristic dissociative attitude would be the result of that ironic aspect rather than its hyperbolic aspect. Cases of 'pure' hyperbole don't convey the characteristic ironical attitude.

Second, it is hard to imagine delivering these lines with the characteristic (deadpan) ironic tone while they remain 'purely' hyperbolic. Hyperboles tend to be delivered with marked stress on the hyperbolically used word or phrase ('tiny', 'impossible', 'million', 'size of Cornwall'), although the utterance as a whole may receive a range of intonation contours depending on several interacting factors (see Claridge 2011). Third, hyperbole doesn't have the normative bias that irony has - it doesn't work more readily when expressing something negative (that is, something that goes against the norm or universal expectation) than something positive. The intended interpretation of a hyperbolic utterance of 'That was the best party ever' describing an enjoyable party is just as accessible as the interpretation of a hyperbolic utterance of 'That was completely horrendous' describing something unpleasant. ${ }^{13}$ So, as Wilson (2013: 54) says, hyperbole doesn't exhibit any of these three characteristic features of

\footnotetext{
${ }^{13}$ The following utterance by Algernon in Oscar Wilde's 'The Importance of Being Ernest' is unequivocally intended by him (if not Wilde) as a positive evaluation: 'I hope, Cecily, I shall not offend you if I state quite frankly and openly that you seem to me to be in every way the visible personification of absolute perfection.' Thanks to Vladimir Žegarac for pointing us to this example.
} 
irony and should not be thought of as a kind of irony.

However, we think that there are something like counterparts to the first two of these characteristics of irony which are paradigmatic characteristics of 'pure' hyperboles and that these counterpart features may go some way towards accounting for why a number of theorists have perceived resemblances between the two figures and classified them together. First, as a counterpart to the dissociative attitude component of irony, there is what could be termed an 'evaluative' component to most hyperboles. Recall that it seems to be a defining feature of hyperbolically used language that it involves a blatant exaggeration, that is, what the speaker literally expresses (but clearly does not mean) is extreme in some contextually relevant way. When we look at typical paraphrases of the intended interpretation of hyperboles we see that what the exaggeration of some property $F$ is used to communicate is that there is more or less of $F$ than the speaker expected (or wanted). So, for (1) the slice of cake is smaller than the speaker expected/wanted; for (3) the number of people in the queue was much greater than she expected/wanted. ${ }^{14}$ In each case, the paraphrase of what the speaker meant doesn't merely capture a quantity or degree which is more factually accurate than the encoded quantity; it also expresses an element of evaluation of the state of affairs described. We suggest that conveying this element of evaluation is part of what the speaker intends to communicate with her hyperbole - it is the crucial interpretive effect of hyperbole (additional to the adjusted propositional content) alluded to in section 2 .

Notice that this evaluative element distinguishes hyperbole from other utterances which are literally/factually inaccurate descriptions of a state of affairs, including approximations and loose uses such as the following:

(13) a. It's 4 o'clock. [when the clock indicates that it is 1 minute and a few seconds before 4 o'clock]

\footnotetext{
14 These are cases where the hyperbole expresses a negative evaluation, but the hyperbolic expression of a positive evaluation is equally possible: e.g. 'That was the best day ever' paraphraseable as 'The day was much better even than I had expected it to be'; 'We finished the job in no time' paraphraseable as 'We finished the job much more quickly than I expected'. This flexibility reflects the absence of a 'normative bias' for hyperbolic utterances.
} 
b. I live in Boston. [when the speaker lives in a suburb 12 miles from Boston's downtown]

c. Holland is flat.

In each of these cases, as in hyperbolic cases, a component of the proposition literally expressed has to be weakened to arrive at a proposition the speaker endorses ('almost 4 o'clock' 'near to Boston', 'flattish' or 'flat for a landscape'), but none of them could be plausibly paraphrased as meaning 'more/less X than the speaker expected/wanted'. So, in conveying this evaluative component, hyperboles do something different from, and not merely 'more extreme' than, what these other loose uses do.

While this evaluative component can be seen as the counterpart in hyperbole of the attitudinal component in irony, it is clear that it is, in fact, quite different from the dissociative ironical attitude. First, as we have seen, there is no specific sort of evaluation required: the full range of positive and negative evaluations across all manner of possible scales is available (smaller/bigger/longer/shorter/harder/easier than I wanted/expected; much worse/better than I was expecting or hoping for). Again, this capacity to convey equally easily both positive and negative evaluations reflects the absence of a normative bias in hyperbole. ${ }^{15}$ Second, it is worth being clear about what exactly it is that is being evaluated by the hyperbolic speaker. Recall that according to the echoic account of irony, the characteristic ironical attitude is being directed towards a thought (attributed to someone other than the speaker at the time of utterance). Somewhat similarly, in pretense accounts of irony, the attitude of pretense is directed at a speech act. This doesn't seem to be what is going on in hyperbole; rather, the positive or negative evaluation is of a state of affairs - the speaker is conveying something evaluative about how she regards the actual state of affairs by exaggerating her description of it.

Clearly, hyperboles are not the only way to convey an evaluation; it can be done

${ }^{15}$ Claridge (2011: 81) notes that, in practice, hyperbolic expressions are more often used to make negative evaluations than to make positive ones. This is an observation about frequencies of occurrence (from counting of instances in corpora) and not about feasibility. As she mentions, it is a manifestation of the same human tendency as is reflected in the heavy tilt towards reporting bad news rather than good news in the press. Nevertheless, the greater frequency of hyperboles expressing negative than positive evaluations may well be a factor in the intuitive grouping of hyperbole with irony. 
literally and explicitly (e.g. 'I have a lot more essays to mark than I would like'), or indirectly via an implicature (e.g. You hand me a pile of essays and I say 'You told me I wouldn't have to do any more marking this year'), or non-literally via a metaphor (e.g. 'John is a bulldozer', 'Mary is a breath of fresh air'). However, neither metaphors nor these other modes of expression necessarily convey an evaluation - this doesn't seem to be their point. Metaphors, for example, may simply contribute to a precise description of how things are (e.g. 'The fields were a patchwork quilt of vivid greens and yellows', 'The fog comes on little cat feet'). By contrast, it is a lot harder to imagine a hyperbole that doesn't come with this evaluative component. ${ }^{16}$ And, although none of the theorists who classify hyperbole with irony have made this point, we suspect that this evaluative aspect of hyperbole might be one of the features that has inclined them to think that it belongs with irony rather than metaphor.

The second respect in which hyperbole and irony have counterpart properties concerns the tone of voice in which they are typically spoken. While it's clear that the ironical tone is not appropriate for 'pure' hyperboles, they seem to have their own rather characteristic tone, which involves a combination of strong accenting of the specific word or phrase used hyperbolically, lengthening of any stressed syllables and a wider pitch range (from high to low) than is used for most non-hyperbolic utterances. This tone might also vary according to the sort of evaluation the speaker is aiming to convey (sounding upbeat, higher in pitch for positive evaluations and lower in pitch - hence more like the ironical tone - for negative evaluations). And as with the typical tone for irony, this characteristic tone functions as a cue for hyperbole, something that helps hearers recognize the exaggeration, but it is not necessary (obviously, all written hyperboles

\footnotetext{
${ }^{16}$ It has been suggested to us that the following are cases of hyperbolic use that are not evaluative: 'It won't take a moment' or 'I'll be back in a second'. While there is something to be explained here - perhaps these are idiomatic (or at least conventionalised reassurances to a hearer) - this sort of case doesn't seem to us to present a strong threat to our claim. For one thing, the overwhelming majority of hyperbolic uses seem to have an evaluative component (see Claridge 2011). At the same time, it is arguable that there is a (minimal) evaluative component in these cases - the speaker is conveying not merely that the required time will be very short, but that it will be so short that the hearer will not be bothered by it.
} 
occur without it and so do many spoken ones). ${ }^{17}$

The upshot so far, then, is that it is clear that hyperbole is not a species of irony, but that, in having these counterpart characteristics, it's not completely unlike irony either (in the way that metaphor, as argued above, is): hyperbole doesn't have a characteristic attitude, but it is characteristic of it that it conveys an evaluation of the situation under discussion and it also has a characteristic tone of voice. It is probably the first of these characteristics in particular that makes hyperbole vulnerable to being classified with irony as it gives rise to the intuition that there is something evaluative going on with both of them.

Robert Fogelin (1988/2011) develops another reason for taking hyperbole and irony to be importantly similar. According to him, both involve similar sorts of 'correcting judgments'. Setting his account against a broadly Gricean background, Fogelin takes the maxim violations produced by both ironic and hyperbolic utterances to '[invoke] mutually recognized correcting responses' in the hearer (2011: 16). In effect, the hearer of an ironic or hyperbolic utterance understands that the uttered sentence is not intended literally/truthfully and 'corrects' it in favor of a more accurate interpretation, which is recovered as an implicature of the utterance. Where irony and hyperbole differ is in the sorts of corrections they provoke. Irony 'reverses polarity' - for example, what sounds like praise is understood to be blame (as in 'You're a great friend'). Hyperbole, by contrast, invites not a reversal but only a weakening of the stated claim - the correcting judgment here moves along a scale from an extreme towards a point closer to the truth. We have already seen the sort of scalar adjustment Fogelin has in mind here in our own examples of hyperbole in (1)-(4). The main problem with Fogelin's position, however, is that his view of irony is completely out of step with the prevailing and empirically well-supported cluster of views of this trope as involving metarepresentation of the proposition literally expressed and an attitude of dissociation from that proposition. He makes no mention of any of these accounts and seems wedded to an early Gricean

\footnotetext{
${ }^{17}$ We are grateful to Jill House (p.c.) for very helpful discussion of the typical prosodic characteristics of hyperbolic speech.
} 
view which Grice himself recognised as inadequate (Grice 1978: 125). ${ }^{18}$

What our examination of accounts that place hyperbole together with irony has revealed is just two rather weak points of resemblance between these two tropes: an evaluative/attitudinal component and a sense that both involve some kind of scalar shift or correction. Before any final assessment of this grouping of hyperbole with irony, we will look into the opposing position - the view that classifies hyperbole with metaphor.

\section{Hyperbole and metaphor}

In contrast with the irony classification just discussed, relevance theorists have long maintained that hyperbole belongs with metaphor (Sperber and Wilson 1985/86, 1986/95, 2008; Wilson and Carston 2006, 2007). The claim is that they are both loose uses of language and require the hearer to form an ad hoc concept which is broader in its denotation than the lexically encoded concept from which it was derived. So, for instance, the word 'boiling' in the following sentence could, in different contexts, be understood hyperbolically or metaphorically, while the comprehension mechanism employed is the same for both interpretations:

(14) The water is boiling.

The idea is that the encoded concepts WATER and BOILING give hearers access to their encyclopedic knowledge about boiling water which might include information such as

\footnotetext{
18 The psychologist Herb Clark also places hyperbole together with irony (and understatement, teasing, sarcasm and rhetorical questions) as involving a kind of joint (speaker-hearer) pretense (what he calls a 'staged communicative act') (Clark 1996). As mentioned in section 3, the pretense view of irony is quite widespread, but Clark is unique, as far as we know, in extending it to hyperbole. While we agree that irony is metarepresentational (as required by a pretense account), we think hyperbole is typically descriptive (and, as discussed above, evaluative) of a state of affairs. The main reason Clark gives for treating hyperbole in this way is that, like irony, it involves a flouting (blatant violation) of the Gricean maxim of truthfulness (ibid: 143), but this applies equally to metaphor and Clark seems not to want to extend the pretense analysis to metaphor, so more argument than this is needed for applying it to hyperbole.
} 
the following:
a. seethes and bubbles, has hidden undercurrents, emits vapour, etc.
b. too hot to wash one's hands in, too hot to bathe in, etc.
c. suitable for making tea, dangerous to touch, etc.

This information differs in its degree of activation in different contexts, hence in its accessibility to the interpreter, so on some occasions the concept expressed by 'boiling' and recovered by pragmatic adjustment of the encoded concept will depend on, say, the information in (15c), other times on (15b) or (15a). The different concepts derived may correspond to what we intuitively judge to be a hyperbolic interpretation or a metaphorical interpretation. For instance, an utterance of (14) made upon turning on a tap and finding the water that comes out uncomfortably hot would likely be judged as hyperbolic, the interpretation depending principally on the encyclopedic information in (15b), while an utterance of (14) made while watching a violent storm at sea would be metaphorical, depending largely on (15a) and not on any information concerning the temperature of the water.

On this view, hyperbolic and metaphorical uses of language are, like other loose uses and all literal uses, descriptive, in that they are representing a state of affairs in the world, while ironical utterances are metarepresentational and 'interpretive' in that they are representing (echoing, according to the relevance-theoretic account) an utterance or a thought or a point of view (and expressing an attitude to it). This is a radically deflationary view of how hyperbole and metaphor work ${ }^{19}$ and of their relation to one another; as mentioned in the introduction, Sperber and Wilson (2008) maintain that they are not genuinely distinct categories from 'descriptive, psycholinguistic, or pragmatic points of view' (2008: 95)..$^{20}$

\footnotetext{
${ }^{19}$ In fact, hyperbole and metaphor are not really construed as tropes or figures at all on this account, but as being on a continuum with mundane non-figurative loose uses such as approximations (e.g. 'a hundred' for 'roughly a hundred') and category extensions (e.g. 'hoover' for 'vacuum cleaner').

${ }^{20}$ Relevance theorists are largely on their own in this classification of hyperbole with metaphor. Wilson (2013) maintains that in classical rhetoric hyperbole was seen as closer
} 
Sperber and Wilson's bold stance flies in the face of the prevailing view of metaphor as a special use of language which should be distinguished from other uses (including hyperbole) and which engages unique interpretive processes. Even if one accepts that both hyperbole and metaphor involve a single interpretive mechanism, such as ad hoc concept formation, there remains a strong intuition that the kinds of interpretation reached are different. One might, for example, hold that metaphors effect a qualitative adjustment of meaning while hyperboles involve merely quantitative shifts. As noted earlier, it's pretty clear that (1)-(4) involve only quantitative adjustments to their encoded meanings (recall our earlier observation that each involves adjustment along a scale). And in contrast to these cases, consider the following metaphor:

(16) The fog comes on little cat feet.

(from Carl Sandburg's poem Fog)

It is equally clear that the fog doesn't literally have feline paws of a more extreme size (or nature) than is typical; rather, it moves over the ground without paws of any kind but in a way that shares features with the stealthy and delicate way that cats sometimes move. In a similar way, the exceedingly agile kinds of jumps which cat feet are capable of performing are excluded altogether from consideration. These are qualitative differences, and one might think that they are rather characteristic of metaphorical utterances, while quantitative differences are characteristic of hyperbolic ones.

In arguing for their continuum view of hyperbole and metaphor, Sperber and Wilson take issue with this way of distinguishing the two. They present examples such as the following which they think are hard to classify as either hyperbolic or metaphorical because, discussing example (17) below, "there is both a quantitative and a qualitative difference ... between a saint and an ordinary kind person" (Sperber and Wilson 2008:

to metaphor than to irony. In fact, however, what both Aristotle and Quintilian seem to stress (along with the 'adolescent vehemence' of much hyperbole) is its co-occurrence with metaphor (and simile). For instance, Aristotle says "Well-liked hyperboles are also metaphors; for example, of a man with a black eye, 'You would have thought him a basket of mulberries', for his face is somewhat purple, but there is much exaggeration. And in 'like this or that' there is hyperbole differing in the form of expression: [...] 'He has legs like stringy parsley' ..." (Aristotle, Rhetoric, Book 3, chapter 11.15). 
94). They see this as undermining the claim that there is a quantitative/qualitative distinction between the two figures:

(17) Susan is a saint. // Susan is an angel.

(18) You're a giant. (Wilson, 2013: 53)

It seems right that there is a qualitative difference between the encoded and figurative interpretations. For example, in (17), the property of being canonized is given up altogether at the same time that those literal saints who are not known for their 'saintly' behavior are excluded from the denotation of the figurative interpretation. And there's also something to the idea that these utterances have a hyperbolic quality, that in each case one has moved to a more extreme point on a quantitative scale (Susan may be virtuous but not to that extremely high degree). On this basis, Sperber and Wilson maintain that (17) and (18) are borderline cases on a hyperbole-metaphor continuum neither falls clearly on exactly one side of a proposed line, and so the idea that there is a line between hyperbole and metaphor seems to be in trouble.

In other work, we have argued against collapsing the hyperbole/metaphor distinction on these grounds (Carston and Wearing 2011). In brief, the thing to say about these cases, we suggest, is not that they are hard to classify because it's unclear where the line is between a hyperbole and a metaphor; instead, we should take these cases as examples which are simultaneously metaphorical and hyperbolic. After all, the classification problem arises precisely because they look as though they are both, and not because they don't quite look as though they are properly or robustly either.

One line of support for this alternative analysis comes from consideration of what seem to be hyperbolic similes, such as the following:

(19) He's as charismatic as a traffic cone.

(20) Her anger radiated like a nuclear explosion.

Examples like these do not tempt one to say that simile constitutes a kind of loose use on the continuum with approximation, hyperbole, and metaphor. For if simile were a case of 
loose use, then the denotation of something in the simile-sentence would undergo broadening, but that doesn't seem to be happening in these examples. In (19), for instance, both 'charismatic' and 'traffic cone' are clearly to be taken as expressing their ordinary literal meanings. So, by parity of reasoning, the fact that something looks hyperbolic and at the same time looks like a metaphor is not evidence that there is no distinction between those two figures.

If we are right that cases like (17) and (18) should be treated as straightforward co-occurrences of hyperbole and metaphor, then the claim that hyperbole and metaphor involve differences in the kind of meaning adjustment required still stands: while hyperbolic uses involve a shift of magnitude or quantity along a scale, metaphorical uses involve a multi-dimensional qualitative shift (often talked of in the literature on metaphor as a 'domain shift'). ${ }^{21}$ Note, though, that this claim does not bear on the kind of pragmatic mechanism employed in the interpretation of metaphor and hyperbole - the account of both in terms of ad hoc concept construction remains intact ${ }^{22}$ - but is entirely a matter of the different kinds of content derived in the two cases and thus the different relation of each to the literal content.

However, even this sharing of the pragmatic interpretive mechanism of ad hoc concept construction may not carry through for all cases of hyperbole. There seems to be an interesting and telling difference between hyperbole and metaphor when they co-occur with irony. It is clear that, when a metaphorically used word or phrase falls within the scope of irony, the propositional representation that is echoed contains the ad hoc concept which is the result of adjusting or modulating the literal meaning of the word or phrase. Consider the following as ironical utterances:

(21) She is the cream in my coffee.

(22) Mary is a gazelle.

\footnotetext{
${ }^{21}$ Recent empirical work also supports the existence of significant differences (descriptive and psycholinguistic, if not pragmatic) between hyperbole and metaphor (Deamer 2013, Rubio Fernandez, Wearing and Carston 2015).

${ }^{22}$ However, independent of the point we are making here, we will suggest in the next section that hyperbolic language use may in fact recruit a range of pragmatic mechanisms, of which ad hoc concept formation is but one.
} 
(23) His hand-writing is fine lacework.

In (21), the attitude of dissociation is expressed towards a thought in which the phrase 'cream in my coffee' has been conceptually adjusted to something paraphraseable as 'my pride and joy', and similarly for 'gazelle' and 'fine lacework' in (22) and (23) respectively. In other words, the ironical stance is taken towards the thought which contains as a component the concept that arises from the process of pragmatic modulation.

Consider now cases of hyperbolically used words and phrases within an ironical utterance:

(24) Thanks for the minuscule piece of cake. (said by a dieter who has just been served a fairly large slice of cake contrary to her earlier expressed wish)

(25) What fabulous good luck I'm having today. (said by someone who has lost her umbrella, just missed her train and then hears that there will be a 20 minute delay before the next one, which will make her late for dinner)

It seems that the thought that is metarepresented and dissociated from in these cases is the literal proposition expressed rather than a representation containing an ad hoc concept recovered by pragmatic weakening of the encoded meaning. In (24), for instance, the description of the piece of cake as miniscule (instead of small) heightens the irony and makes detection of the ironic attitude easier. ${ }^{23}$ In other words, the excessiveness of the metarepresented propositional content plays a very helpful role in cuing the dissociative attitude of the speaker. If it were first adjusted then that clue to the intended ironical meaning would be lost and even if a dissociative attitude were recognised the proposition echoed would less obviously be a thought to be derided. It seems, then, that when used ironically, hyperboles and metaphors play different kinds of role: the literal content of a hyperbole serves to cue and heighten the irony, while the literal content of a metaphor must be adjusted in order to recover the thought at which the irony is directed.

\footnotetext{
${ }^{23}$ Kreuz and Roberts (1995) have shown that the presence of hyperbole significantly increases the detection of verbal irony and, in a somewhat related vein, Colston and O'Brien (2000) have found that hyperbolic ironies are understood as more humorous, condemning, or speaker-protecting than 'weaker' (non-hyperbolic) ironies.
} 
Let us now sum up our discussion of the relevance-theoretic classification of hyperbole with metaphor. What is right about this grouping is that hyperbole and metaphor share certain characteristics that distinguish them both from irony: (i) descriptiveness, that is, their propositional content represents a state of affairs in the world (as distinct from the metarepresentational nature of irony), (ii) their meaning gets 'lodged in the words', thus affects the propositional content, (iii) the pragmatic mechanism involved in both cases is (usually) one of lexical adjustment (or word meaning modulation, as Recanati (2004) puts it). ${ }^{24}$ Where metaphor and hyperbole differ from each other, though, is in the evaluative component, which is typical of hyperbolic uses but not of metaphor and which is often where the main point of the hyperbole lies. ${ }^{25}$ It is notable in this respect that we generally have little difficulty finding an adequate paraphrase for a hyperbolically used word: 'boiling' is used to mean 'uncomfortably hot', 'trillions of essays' to mean 'a much larger number of essays than wanted/expected', etc., while, as is frequently noted, it is very much harder to find an even moderately adequate

${ }^{24}$ An anonymous referee for the journal has noted the phenomenon in casual speech of using hyperbole together with the modifier 'literally', as in 'There were literally gazillions of people at the party'. This seems to be possible with (at least some cases of) metaphor too, e.g. 'He literally exploded with rage', but not with irony, e.g. 'It's literally lovely weather'. We can't attempt a precise analysis of this here, but it seems likely that either 'literally' is itself being used loosely or it is being used as an intensifier of the broadened ad hoc concept inferred from hyperbolic and/or metaphoric uses of words.

${ }^{25}$ In contrast to the observation made in the previous footnote, hyperbole lines up with irony rather than metaphor in the following respect. While the phrase 'metaphorically speaking' can be appended to a metaphorical use without infelicity (e.g. 'When you are at the cliff edge, do not be afraid - jump and you will fly, metaphorically speaking' (attested case)), the same does not hold for the phrase 'hyperbolically speaking'. To say 'Hyperbolically speaking, the queue was a mile long' seems to destroy the hyperbolic effect and sounds distinctly odd. This difference in acceptability may be connected to the evaluative nature of hyperbole, which, as noted in section 4, also distinguishes it from approximations and other cases discussed by Sperber and Wilson as falling on their continuum of loose uses. As with metaphor, we find that phrases that make these kinds of loose use explicit seem to be fine (e.g. 'It's approximately 4 o'clock', 'France is, loosely speaking, hexagonal'). In this respect, then, hyperbole is like irony: appending the phrase 'Ironically speaking' to an ironical utterance also undermines the felicity of the utterance (e.g. 'Ironically speaking, you've done a great job'). It seems that both the evaluative effect (in hyperbole) and the dissociative attitude (in irony) must remain implicit, must be inferred by the hearer on the basis of other clues: in the case of hyperbole, patently exaggerated content and specific prosodic features. 
paraphrase of metaphorical uses (consider, e.g., 'Mary is a bulldozer'; 'His life was a skiff with no oar'; 'Juliet is the sun'). We suggest that this is because the two figures are essentially different in purpose: metaphor is a bid to give precise expression to a thought or experience for which there is no literal linguistic encoding, while what is fundamental to hyperbole is the expression of an evaluation (positive or negative) of a state of affairs. $^{26}$

We end this section with a brief review of what has emerged from our examination of attempts to assimilate hyperbole to irony, on the one hand, and to metaphor, on the other. We've seen that there are grounds for both answers to the 'metaphor or irony?' question: hyperbole is somewhat like irony in its evaluative nature while it is like metaphor in being descriptive of a state of affairs (and in usually requiring an adjustment to linguistically encoded content). It is, however, different from irony in not being inherently metarepresentational as the latter seems to be (echoic or pretense involving) and from metaphor in being essentially evaluative and merely quantitative in the meaning shift it requires. ${ }^{27}$

${ }^{26}$ It's also worth noting in this regard that while extended metaphors, often developed over whole poems or paragraphs, are quite common, the phenomenon of extended hyperboles is relatively rare. Relatedly, while the concept of 'metaphorical worlds' is active (in literary studies, psychotherapy, and other fields), no one seems to have found application for a concept of 'hyperbolic worlds'.

${ }^{27}$ Further evidence for treating hyperbole as importantly different from both irony and metaphor may emerge from work in developmental pragmatics. If, for example, it could be shown that hyperbole follows a developmental trajectory which is significantly different from that of both metaphor and irony, this would give further support to the position that it should be treated as an interestingly distinct trope. As noted in section 3, there are numerous studies that indicate that children's ability to produce and understand metaphor comes online well before they can handle irony (e.g. Winner 1988), which is not surprising given the greater representational complexity of irony. However, there is as yet very little investigation into children's use of hyperbole and how it compares with their metaphor and irony development. An interesting study of children's use of irony in naturalistic family conversations includes cases of hyperbolic irony (Recchia et al. 2010), but does not trace hyperbolic use per se. Filippova and Astington (2010) examine comprehension of hyperbolic irony under more controlled conditions, but non-ironic hyperbole is not studied (cf. footnote 10 above). Varga's (2000) observations of preschool children's language play records cases of hyperbolic language produced by fourand-a-half year olds, which is several years before the use of irony. The only study we 


\section{How hyperbole works}

In this paper, we have used the two central tropes, metaphor and irony, with their clearly distinct properties, as a means of examining the nature of the much less studied trope, hyperbole, and have found that, although hyperbole has some features in common with each of these figures, it does not align any more with one than the other and it differs from both in important ways. It is thus time to abandon classifications that situate hyperbole neatly with metaphor or with irony and accept that it isn't really like either of them but works in its own distinctive way with its own distinctive interpretive effects.

A key feature of hyperbole, we have claimed, is its evaluative component (which may be positive or negative). In virtue of the exaggerated nature of its representation of a state of affairs (which is mutually manifest to speaker and hearer), a hyperbolic use of language typically carries a strong implication that the speaker finds the situation she is describing to have (much) more of some property than she expected or wanted. Conveying this evaluation is a central objective of speaking hyperbolically. But what the discussion in the preceding sections has shown is that this evaluative effect can arise in conjunction with a variety of pragmatic processes or mechanisms. It can be achieved directly via loose use (concept broadening) as in our examples of 'pure' hyperbole (e.g. 'I have trillions of essays to mark', 'My piece of cake is minuscule') or indirectly via a metaphor (e.g. 'she is an angel/an iceberg') or comparable cases of simile (e.g. 'she is

know of which directly compares children's comprehension of hyperbole and metaphor is a set of experiments by Felicity Deamer (2013; see also Deamer and Pouscoulous forthcoming), in which she found that three-year-olds were significantly better at interpreting hyperboles than metaphors and that their independently tested ability for 'inhibitory control' correlated strongly with their metaphor comprehension but not with their hyperbole comprehension. She tentatively suggests that this may indicate that metaphorical competence requires a developed capacity for inhibitory control, while hyperbolic competence does not. Clearly, follow-up studies are needed but, if further empirical work corroborates these findings, it may turn out that hyperbole follows a distinct (and earlier) developmental path from that of both irony and metaphor. This sort of empirical evidence would support the theoretical stance we have argued for in this paper. Thanks to an anonymous referee for raising this point. 
like an angel/an iceberg). In these cases, there is a felt gap between how things are described and how they are known (or believed) to be. Hyperbole also arises in metarepresentational uses of language such as irony and parody (e.g. 'it was the most stimulating lecture ever' [describing a tedious lecture], 'She absolutely wouldn't dream in a million years of intimating in even the most tenuous way that anything about her life is other than totally wonderful' [describing someone's way of talking about herself]. Here, the exaggeration again relies on the evident gap between what is the case and what the speaker could reasonably be taken to believe, but it does not result in adjustment of the encoded concept. Instead, its effect in cases of irony and parody is to encourage the recognition of an attitude of dissociation from the proposition expressed (and probably also to strengthen the ironic attitude recovered).

None of these uses of language is inherently hyperbolic. As we have seen, there are loose uses, such as approximations (e.g. 'It's 4 o'clock') and category extensions (e.g. 'She quickly hoovered the hall carpet'), which are not hyperbolic (and do not involve any evaluative component). There are metaphors and similes which are attempts to achieve precise expression of an experience rather than anything evaluative (e.g. 'The sea was a distant shimmer of silver foil and the houses of the village were (like) matchbox toys'). And irony does not depend on hyperbole even though the latter is a helpful and fairly frequent cue to the former, so non-hyperbolic utterances like 'well done', 'thanks for your help', 'happy days' are readily understood as ironical in the right context. Each of these uses of language (irony, metaphor, loose use, etc.) exists independently of hyperbole and is underwritten by some set of pragmatic mechanisms or other (which ones those are will depend on your view of how metaphor, irony, etc. work).

Our claim is that no one of the mechanisms at work in these other uses is sufficient on its own to explain all cases of hyperbole, for no one of them is present in every hyperbolic use. Rather, hyperbole works by exploiting a range of independently motivated pragmatic mechanisms. In other words, the speaker who offers a clearly recognizable exaggeration can achieve the specific evaluative effect which we have argued is characteristic of hyperbole by means of either adjustment of descriptive meaning, whether a simple loose use or a more complex meaning shift as in metaphor, or 
a metarepresentational use of the sentence she utters, and (perhaps by other means too ${ }^{28}$ ). At root, then, the hyperbolic use of language is a very simple phenomenon, depending only on a salient quantitative shift toward the extreme end of a scale. Its frequency of use and of co-occurrence with other figures is explainable, at least in part, by this capacity to recruit a range of pragmatic mechanisms.

For all its simplicity, however, we should not lose sight of the creative power which hyperbole can achieve. We have focused for the most part on fairly mundane spontaneous conversational cases of hyperbole, but it's worth noting that the figure encompasses a much wider range, from banal cases such as those involving movement along a standard numerical or other measurement scale ('supermarket queue a mile long', 'gargantuan paunch', 'minuscule piece of cake') to much more imaginative and/or imagistic cases such as (4) above, repeated here, and the attested case in (28):

(4) Sara's bedroom is the size of Cornwall.

(26) 'Every word she says is a lie, including "and" and "the".'

[Mary McCarthy on Lillian Hellman, Independent Radar/books 07/07/2012, p. 30.]

Both are patently absurd and involve an imaginative leap that extends the scales being invoked beyond anything like their normal extreme points (for size of bedrooms; for the use of language to tell lies). In creative examples like these, then, it's not just the proposition literally expressed that is hyperbolic: the hearer of (4) has to entertain the possibility of a size scale that runs all the way through the dimensions of small and large bedrooms to those of land masses constituting counties or provinces; the hearer of (26)

\footnotetext{
${ }^{28}$ This may include certain literal uses as well. We have in mind here cases of hyperbolic simile, e.g. 'You behave like a psychopath', 'She's as mean as a wounded bear', where, arguably, the meaning of the simile vehicle, 'psychopath', 'wounded bear', is not adjusted to an ad hoc concept, as metaphorical uses are, but rather implicatures are derived directly from the encoded literal meaning (for some preliminary discussion, see Carston and Wearing 2011).
} 
has to briefly play with the possibility of telling lies with words ('and' and 'the') that are not truth-evaluable or even contentful. In this respect, hyperbole is no different from metaphor, simile or other tropes that affect the propositional content of utterances (or texts) - once we are in the realm of language uses that depart from factual representation, the scope of these uses is only limited by the reaches of the human imagination. 


\section{Acknowledgements}

We are grateful to Felicity Deamer and Nausicaa Pouscoulous for their support and good advice on developmental issues. This work is part of a project, funded by the Leverhulme Trust, called 'Understanding Metaphor: Ad hoc Concepts and Imagined Worlds' (Ref: F/07 134/DP).

\section{References}

Aristotle. Rhetoric. (trans. W. Rhys Roberts, available online from http://classics.mit.edu/Aristotle/rhetoric.html)

Bryant, Greg. 2010. Prosodic contrasts in ironic speech. Discourse Processes 47: 545566.

Cano Mora, Laura. 2009. All or nothing: A semantic analysis of hyperbole. Revista de Lingüística y Lenguas Aplicadas 4: 25-35.

Carston, Robyn and Catherine Wearing. 2011. Metaphor, hyperbole and simile: A pragmatic approach. Language and Cognition 3(2): 283-312.

Claridge, Claudia. 2011. Hyperbole in English: A Corpus-Based Study of Exaggeration. Cambridge University Press.

Clark, Herbert H. 1996. Using Language. Cambridge University Press.

Clark, Herbert H. and Richard J. Gerrig. 1984. On the pretense theory of irony. Journal of Experimental Psychology: General: 113: 121-6. (Reprinted in Gibbs and Colston 2007: 25-33.)

Colston, Herbert L. and Raymond Gibbs. 2002. Are irony and metaphor understood differently? Metaphor and Symbol 17: 57-80.

Colston, Herbert L. and Jennifer O'Brien. 2000. Contrast of kind versus contrast of magnitude: the pragmatic accomplishment of irony and hyperbole. Discourse Processes 30 (2): 179-199.

Currie, Gregory. 2006. Why irony is pretence. In: S. Nichols (ed.) The Architecture of the Imagination. Oxford University Press, Oxford, pp. 111-133. 
Deamer, Felicity. 2013. An investigation into the processes and mechanisms underlying the comprehension of metaphor and hyperbole. $\mathrm{PhD}$ dissertation, University College London.

Deamer, Felicity and Nausicaa Pouscoulous. Forthcoming. Non-literal children: Preschoolers' understanding of figurative language.

Filippova, Eva and Janet W. Astington. 2010. Children's understanding of socialcognitive and social-communicative aspects of discourse irony. Child Development 81 (3): 913-928.

Fogelin, Robert J. 1988/2011. Figuratively Speaking. New Haven and London: Yale University Press. (Second (revised) edition, Oxford University Press, 2011.)

Gibbs, Raymond and Herbert L. Colston. 2007. Irony in Language and Thought. Hillsdale NJ: Lawrence Erlbaum

Goodman, Nelson. 1968. The Languages of Art. Indianapolis: Bobbs-Merrill.

Grice, H. Paul. 1978. Further notes on logic and conversation. In P. Cole (ed.) Syntax and Semantics 9: Pragmatics, 113-127. New York: Academic Press. Reprinted in H. P. Grice 1989: 41-57.

Grice, H. Paul. 1989. Studies in the Way of Words. Cambridge, Mass.: Harvard University Press.

Guttenplan, Samuel. 2005. Objects of Metaphor. Oxford: Clarendon Press.

Happé, Francesca G. E. 1993. Communicative competence and theory of mind in autism: A test of Relevance theory. Cognition 48: 101-119.

Hills, David. 1997. Aptness and truth in verbal metaphor. Philosophical Topics 25 (1): 117-153.

Kreuz, Roger J. and Richard M. Roberts. 1995. Two cues for verbal irony: Hyperbole and the ironic tone of voice. Metaphor and Symbolic Activity 10: 21-31.

Kreuz, Roger. J., Richard M. Roberts, Brenda K. Johnson and Eugenia L. Bertus. 1996. Figurative language occurrence and co-occurrence in contemporary literature. In: R. J. Kreuz and M. S. MacNealy (eds.), Empirical Approaches to Literature and Aesthetics, 83-97. Norwood, NJ: Ablex Publishing Corp.

Kreuz, Roger J., Max A. Kassler and Lori Coppenrath. 1998. The use of exaggeration in discourse: Cognitive and social facets. In: S. R. Fussell \& R. J. Kreuz (eds.), Social 
and Cognitive Approaches to Interpersonal Communication, 91-111. Mahwah, NJ: Lawrence Erlbaum Associates.

Kumon-Nakamura, Sachi, Sam Glucksberg and Mary Brown. 1995. How about another piece of pie: the allusional pretense theory of discourse irony. Journal of Experimental Psychology: General 124: 3-21. Reprinted in R. Gibbs and H. L. Colston (eds.) 2007: 57-95.

Langdon, Robyn, Martin Davies and Max Coltheart. 2002. Understanding minds and communicated meanings in schizophrenia. Mind and Language 17(1/2): 68-104.

Leggitt, John S. and Raymond Gibbs. 2000. Emotional reactions to verbal irony. Discourse Processes 29 (1): 1-24.

McCarthy, Michael and Carter, Ronald, 2004. "There's millions of them": hyperbole in everyday conversation. Journal of Pragmatics 36: 149-184.

Norbury, Courtenay F. 2005. The relationship between theory of mind and metaphor: Evidence from children with language impairment and autistic spectrum disorder. British Journal of Developmental Psychology 23: 383-399

Norrick, Neal, R. 2004. Hyperbole, extreme case formulation. Journal of Pragmatics 36: 1727-1739.

Recanati, Francois. 2004. Literal Meaning. Cambridge: Cambridge University Press. Recchia, Holly, Nina Howe, Hildy Ross, and Stephanie Alexander. 2010. Children's understanding and production of verbal irony in family situations. British Journal of Developmental Psychology 28: 255-274.

Rockwell, Patricia. 2000. Lower, slower, louder: vocal cues of sarcasm. Journal of Psycholinguistics Research 29: 483-495. 29

Rubio Fernandez, Paula, Catherine Wearing and Robyn Carston. 2015. Metaphor and hyperbole: Testing the Continuity Hypothesis. Metaphor and Symbol 30 (1): 24-40. Sperber, Dan and Deirdre Wilson. 1985/86. Loose talk. Proceedings of the Aristotelian Society 86: 153-171. Reprinted in S. Davis (ed.) 1991, Pragmatics: A Reader, 540549. Oxford: Oxford University Press.

Sperber, Dan and Deirdre Wilson. 1986/95. Relevance: Communication and Cognition. London and New York: Blackwell. 
Sperber, Dan and Deirdre Wilson. 2008. A deflationary account of metaphors. In: R. Gibbs (ed.), The Cambridge Handbook of Metaphor and Thought, 84-105. Cambridge: Cambridge University Press.

Stern, Josef. 2000. Metaphor in Context. Cambridge Mass.: MIT Press.

Varga, Donna. 2000. Hyperbole and humour in children's language play. Journal of Research in Childhood Education 14 (2): 142-151.

Wilson, Deirdre. 2013. Irony comprehension: A developmental perspective. Journal of Pragmatics 59: 40-56.

Wilson, Deirdre and Robyn Carston. 2006. Metaphor, relevance and the 'emergent property' issue. Mind and Language 21 (3): 404-433.

Wilson, Deirdre and Robyn Carston. 2007. A unitary approach to lexical pragmatics: Relevance, inference and ad hoc concepts. In: N. Burton-Roberts (ed.). Pragmatics, 230-259. Basingstoke and New York: Palgrave Macmillan.

Wilson, Deirdre and Dan Sperber. 1992. On verbal irony. Lingua 87: 53-76. Reprinted in R. Gibbs and H. L. Colston (eds.) 2007: 35-55..

Wilson, Deirdre and Dan Sperber. 2012. Explaining irony. In: D. Wilson and D. Sperber Meaning and Relevance, 123-145. Cambridge: Cambridge University Press.

Winner, Ellen. 1988. The Point of Words: Children's Understanding of Metaphor and Irony. Cambridge Mass.: Harvard University Press. 